\section{A case of chronic ulcer due to subcutaneous arteriolosclerosis in an obese patient mimicking pyoderma gangrenosum}

\author{
Sezin Fıçıcıoğlu, ${ }^{1}$ Nuray Can, ${ }^{2}$ \\ Busem Tutuğ $\breve{g}^{2}$ \\ ${ }^{1}$ Department of Dermatology; and \\ ${ }^{2}$ Department of Pathology, Trakya \\ University Faculty of Medicine, Edirne, \\ Turkey
}

\begin{abstract}
The differential diagnosis of chronic ulcers covers a wide range of diseases and poses a diagnostic challenge. Subcutaneous ischemic arteriolosclerosis can lead to local ischaemia and ulceration as a result of arteriolar narrowing and reduction of tissue perfusion. This pathophysiological feature can be seen in eutrophication (nonuremic calciphylaxis) in morbid obesity, hypertensive ischemic leg ulcer (Martorell ulcer) and calciphylaxis in chronic renal insufficiency. All of the ulcers happened in this way can be wrongly diagnosed as pyoderma gangrenosum because of clinical similarity and inadequate biopsies. We report a case of chronic ulcer due to subcutaneous arteriolosclerosis in morbid obesity, wrongly diagnosed as pyoderma gangrenosum. It can be detrimental to misdiagnose the ulcers due to subcutaneous arteriolosclerosis as pyoderma gangrenosum since they need a diametrically different approach.
\end{abstract}

\section{Introduction}

The differential diagnosis of chronic ulcers covers a wide range of diseases and poses a diagnostic challenge. ${ }^{1,2}$ The clinical presentations, underlying etiology, and pathological manifestations of the ulcers are major clues to make the diagnosis.

Hafner reviewed four diseases: i) calciphylaxis (distal patern); ii) calciphylaxis (proximal patern); iii) Martorell hypertensive ischemic leg ulcer; iv) calciphylaxis with normal renal and parathyroid function (eutrophication) all having the same clinical features as necrotizing livedo, skin infarctions and ulcerations at typical locations. Hafner stated that these four diseases largely share the same risk factors including arterial hypertension, diabetes mellitus (types 1 and 2), secondary or tertiary hyperparathyroidism (in end-stage kidney disease) and oral anticoagulation with vitamin $\mathrm{K}$ antagonists. $^{3}$ Also a shared histopathology has been stated in these diseases: subcutaneous ischemic arteriolosclerosis characterized by a medial calcinosis and stenosis due to thickening of the vessel wall (hyperplasia of the smooth muscle layer) and/or intimal hyperplasia. ${ }^{2-4}$ Hafner et al..$^{5}$ suggested the term uremic small artery disease with medial calcification and intimal hyperplasia instead of the customary denomination calciphylaxis. In 1992 Ramsey-Stewart reported a case of progressive dermatoliponecrosis in a morbidly obese patient and suggested the term eutrophication for. Even though he did not investigate the existance of subcutaneous arteriolosclerosis he claimed that in obese people inadequate peripheral tissue perfusion affects the apex of grossly dependent adipose folds and leads patchy gangrenous changes and skin infartions. ${ }^{6}$

\section{Case Report}

A 44-year-old man who had Nissen fundoplication and incisional hernia repair operation one year and three months ago respectively, referred to our hospital for a linear necrotic ulcer $15 \mathrm{~cm}$ in length $5 \mathrm{~cm}$ in width at the anterior abdomen, on incision line. He had type 2 diabetes mellitus for five years, no hypertension or renal insufficiency and he was obese as his body mass index was $31.1 \mathrm{~kg} / \mathrm{m}^{2}$. The ulcer first appeared after removing the sutures of incisional hernia repair and rapidly enlarged. After surgical debridement of necrotic tissues and three sessions of negative pressure wound therapy with vacuum dressings, a prominent effect was not observed. The ulcer kept on growing, reached $15 \times 10 \mathrm{~cm}$ dimensions with raised and rolled undermining margins (Figure 1A). By the way the incisional biopsy taken from the edge of the ulcer concluded as pyoderma gangrenosum. After taking $80 \mathrm{mg} /$ day methylprednisolone for one week the ulcer got worse, enlarged and deepened (Figure 1B). Systemic steroid treatment stopped and a second biopsy was taken in a large elliptical shape starting from healthy skin at the ulcer edge extending into the fascia. Histological examination revealed subcutaneous arteriolosclerosis with thickened arteriole walls and narrowed lumens and Von Kossa staining also displayed the calcification in the vessel walls (Figure 2). Serum concentration of urea was $14 \mathrm{mg} / \mathrm{dL}$ [normal range (nr): 19-50], creatinine was $0.73 \mathrm{mg} / \mathrm{dL}$ (nr: 0.72-1.25), parathyroid hormone was $32.5 \mathrm{pg} / \mathrm{mL}$ (nr: 11-88), calcium was $10.1 \mathrm{mg} / \mathrm{mL}$ (nr: 8.8 10.6) and phosphate was $3.3 \mathrm{mg} / \mathrm{mL}(\mathrm{nr}$ :
Correspondence: Sezin Fiçıcıoğlu, Trakya Üniversitesi Tip Fakültesi, Dermatoloji Anabilim Dalı, Balkan Yerleşkesi, 22030 Edirne, Turkey.

Tel.: +90.284.2357641 - extension: 1282 E-mail: sezinkuru@hotmail.com

Key words: Arteriolosclerosis; eutrophication; pyoderma gangrenosum; calciphylaxis.

Authors' contributions: SF had participated in the study, in conception and design, analysis and interpretation of data, drafting the article and final approval of the version. NC and BT had participated in the study in analysis and interpretation of data, revising it critically for important intellectual content and final approval of the version.

Conflict of interest: the authors declare no potential conflict of interest.

Received for publication: 13 October 2017. Accepted for publication: 16 March 2018.

This work is licensed under a Creative Commons Attribution-NonCommercial 4.0 International License (CC BY-NC 4.0).

(C) Copyright S. Fiçıcıoğlu et al., 2018

Licensee PAGEPress, Italy

Dermatology Reports 2018; 10:7445

doi:10.4081/dr.2018.7445

2.5-4.5), alanine aminotransferase was 5 U/L (nr: 0-50), aspartate aminotransferase was $15 \mathrm{U} / \mathrm{L}$ (nr: 0-50), gamma-glutamyl transferase was $27 \mathrm{U} / \mathrm{L}$ (nr: 0-55), total bilirubin was $0.2 \mathrm{mg} / \mathrm{dL}$ (nr: 0.3-1.2), direct bilirubin was $0.1 \mathrm{mg} / \mathrm{dL}$ (nr: $0-0.2$ ). His other liver function parameters including prothrombin time test, serum protein electrophoresis and abdominal ultrasonography were in normal limits. Also he had no history of weight loss, pain, fever, fatique, persistent cough or hoarseness, no change in bowel habits and no finding of lymphadenopathy in physical examination. With these clinical and laboratory findings we ruled out uremic calciphylaxis, liver failure, neoplasia and made the diagnosis of eutrophication (nonuremic calciphylaxis). After six more sessions of negative pressure wound therapy with vacuum dressings, split thickness skin grafting was done successfully.

\section{Discussion}

Eutrophication or nonuremic calciphylaxis or calciphylaxis in normal renal function affects morbidly obese people who has also arterial hypertension and type 2 diabe- 
tes mellitus. It is characterized by rapid appearance of progressive skin infarctions in places where fatty tissue is particularly thick such as inner thigh, fatty abdominal apron, breasts or outer upper arms. ${ }^{3,4}$ The skin infarction begins with a painful livedoid area and becomes necrotic with progressive livid margins. Histologically arterioles show massive thickening of the vessel wall (hyperplasia of the smooth muscle layer) leaving a narrow lumen which is often thrombosed. This subcutaneous ischemic arteriolosclerosis is a common pathophysiological feature also in Martorell hypertensive ischemic leg ulcer, calciphylaxis in chronic renal insufficiency. All of them can lead to local ischaemia and ulceration as a result of arteriolar narrowing and reduction of tissue perfusion. ${ }^{2,3,7}$

On the other hand, pyoderma gangrenosum (PG) is a rare neutrophilic inflammatory skin disease presenting with painful sterile ulcerations. Its etiology remains unknown however it is commonly associated with inflammatory bowel disease, rheumatoid arthritis, hematologic malignancies and disorders. ${ }^{89}$ Also it may occur in areas of trauma or surgery; a phenomenon called pathergy. ${ }^{10}$ Jockenhöfer et al. ${ }^{11}$ also suggested an association of obesity and PG.

Our patient was a confusing case as he did not have a disorder like inflammatory bowel disease, rheumatoid artritis or hematologic malignancy but he was obese, had a surgery before the ulceration, his ulcer with livid margins and undermining edges enlarged progressively directing us to the diagnosis of PG. After the pathological confirmation of pyoderma gangrenosum we decided to start systemic steroids which are often the first choice drugs for PG along with other immunosuppressive treatments. But he did not benefit from steroid treatment and even it aggravated the ulcer.

The ulcers mentioned above whose shared histopathology was subcutaneous ischemic arteriolosclerosis can be wrongly diagnosed as pyoderma gangrenosum because of clinical similarity and inadequate biopsies. 3,4,12 Moreover, superficial biopsy samples taken from many types of chronic wound base can be misdiagnosed as pyoderma gangrenosum because necrotic dermis with sheets of neutrophil granulocytes can be found. In a study by Hafner et al. ${ }^{4} 50 \%$ of 31 cases of Martorell ulcers were misdiagnosed as pyoderma gangrenosum and $20 \%$ as necrotizing vasculitis. So in the suspicion of eutrophication and other ulcers caused by subcutaneous arteriolosclerosis, biopsies should be of sufficient depth extending into the subcutis. Our case's not the first but the second biopsy which was taken in a large elliptical shape starting from healthy skin at the ulcer edge extending into the fascia yielded the subcutaneous arterioles with hyperplasia of the smooth muscle layer and narrowing of the lumen. Our patient's ulcer did not begin spontaneously but occured after the surgery on the incision line but it is not contradictory to the eutrophication (nonuremic calciphylaxis) theory as the subcutaneous arteriolosclerosis and decreased tissue perfusion did not allow the cutt to heal and enlarged the ulcer.

It can be detrimental to misdiagnose eutrophication (nonuremic calciphylaxis) and other subcutaneous arteriolosclerotic ulcers as pyoderma gangrenosum since they need a diametrically different approach. Pyoderma gangrenosum needs systemic steroid treatment and surgical approaches are
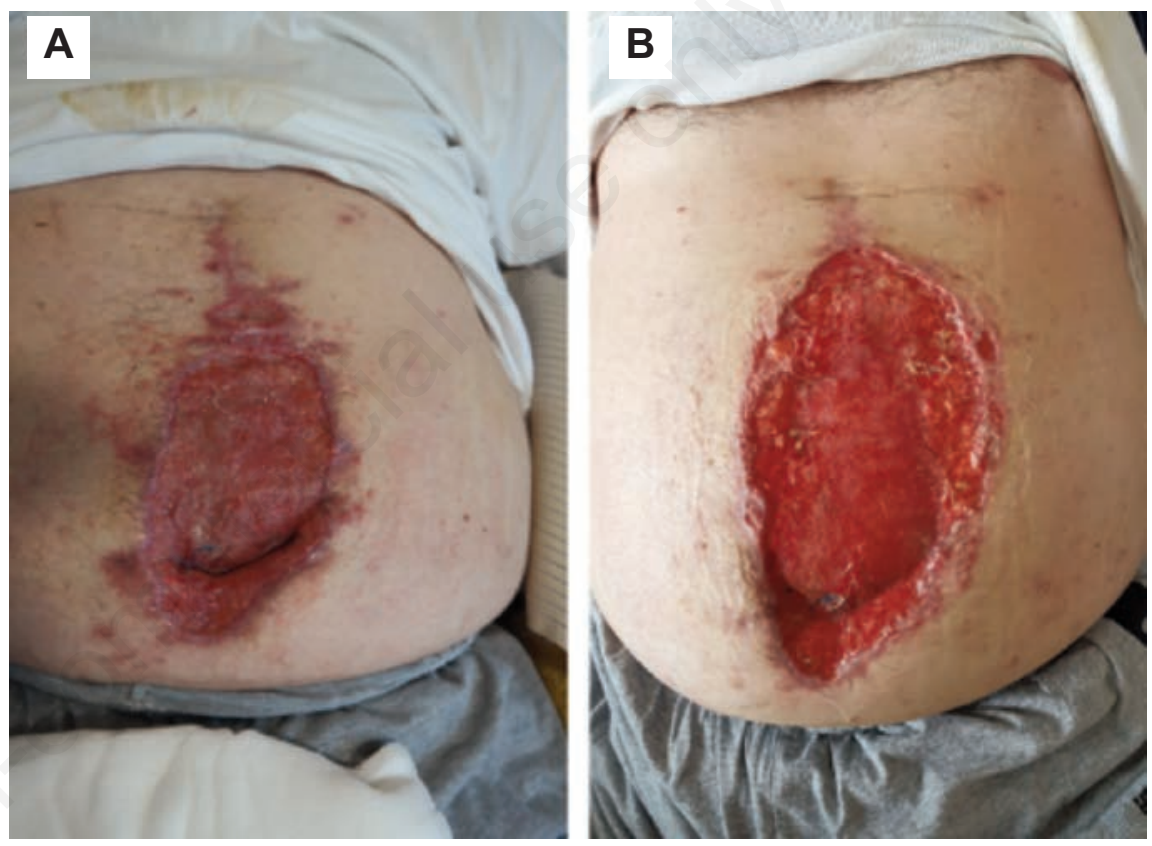

Figure 1. The ulcer on the incision line at the anterior abdomen had livid undermined margins resembling pyoderma gangrenosum, before steroid treatment $(\mathrm{A})$ and after taking $80 \mathrm{mg} /$ day methylprednisolone for one week the ulser enlarged and deepened (B).
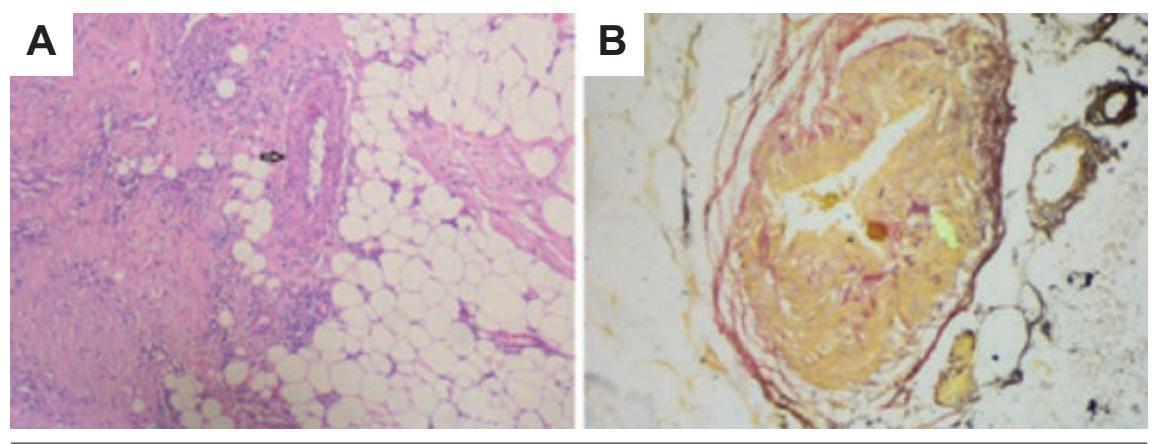

Figure 2. A) Subcutaneous arteriole (black arrow) shows hyperplasia of smooth muscle layer, narrowing of the lumen and increased wall-to-lumen ratio resulting in skin infarction leading to ulceration (hematoxylin-eosin, original magnification $\times 10$ ). B) Von Kossa staining ( $\times 20)$ shows vessel calcification (yellow arrow) in addition to narrowing of the lumen. 
rity with these disorders should be improved especially because of the risk of confusion with pyoderma gangrenosum. And our case demonstrates that he is wright.

\section{References}

1. Novinscak T, Filipovic M, Edita J, et al. Surgical approach to atypical wounds (clinical cases). Subcutaneous ischemic arteriolosclerosis (Martorell ulcer, calciphylaxis, eutrophication). Acta Med Croatica 2012;66:139-45.

2. Alavi A, Hafner J, Sibbald RG. Martorell hypertensive ischemic leg ulcer: an underdiagnosed entity. Adv Skin Wound Care 2012;25:563-72.

3. Hafner J. Calciphylaxis and Martorell hypertensive ischemic leg ulcer: same pattern - one pathophysiology. Dermatology 2016;232:523-33.

4. Hafner J, Nobbe S, Partsch H, et al.
Martorell hypertensive ischemic leg ulcer: a model of ischemic subcutaneous arteriolosclerosis. Arch Dermatol 2010;146:961-8.

5. Hafner J, Keusch G, Wahl C, et al. Uremic small-artery disease with medial calcification and intimal hyperplasia (so-called calciphylaxis): a complication of chronic renal failure and benefit from parathyroidectomy. J Am Acad Dermatol 1995;33:954-62.

6. Ramsey-Stewart G. Eutrophication: spontaneous progressive dermatoliponecrosis. A fatal complication of gross morbid obesity. Obes Surg 1992;2:263-4.

7. Vuerstaek JDD RS, Henquet CJM, Neumann HAM. Arteriolosclerotic ulcer of Martorell. JEADV 2010;24:867-74.

8. Al Ghazal P, Korber A, Klode J, Dissemond J. Investigation of new cofactors in 49 patients with pyoderma gangrenosum. J Dtsch Dermatol Ges 2012;10:251-7.

9. Vallini V, Andreini R, Bonadio A. Pyoderma gangrenosum: a current problem as much as an unknown one. Int J Low Extrem Wounds 2017; 16:191-201.

10. Urman CO, Ashby-Richardson H, Thakker PS. Pyoderma gangrenosum following gastric bypass surgery. Cutis 2014;93:261-3.

11. Jockenhofer F, Herberger K, Schaller J, et al. Tricenter analysis of cofactors and comorbidity in patients with pyoderma gangrenosum. J Dtsch Dermatol Ges 2016;14:1023-30.

12. Kolios AGA, Hafner J, Luder C, et al. Comparison of pyoderma gangrenosum and hypertensive ischemic leg ulcer Martorell in a Swiss cohort. $\mathrm{Br} \mathrm{J}$ Dermatol 2017 [Epub ahead of print]. 